\title{
Metabolic Fate of L-Arginine in Relation to Microbiostatic Capability of Murine Macrophages
}

Donald L. Granger, ${ }^{\star}$ John B. Hibbs, Jr., ${ }^{\ddagger}$ John R. Perfect, ${ }^{\star}$ and David T. Durack ${ }^{\star}$

${ }^{*}$ Division of Infectious Diseases in the Department of Medicine, Duke University, Durham, North Carolina 27710; ${ }^{\ddagger}$ Division of Infectious Diseases, Veterans Administration Medical Center, and University of Utah College of Medicine, Salt Lake City, Utah 84145

\begin{abstract}
L-arginine is required for the fungistatic action of murine macrophages in vitro. To further investigate this requirement, $\mathrm{L}$-arginine metabolism by macrophages was measured under conditions where fungistasis either succeeded or failed. Macrophage fungistasis correlated with metabolism of $L$-arginine to citrulline, nitrite, and nitrate. The metabolic rate was dependent on extracellular $L$-arginine concentration, reaching a maximum of $67 \mathrm{nmol}$ nitrite/h per $\mathrm{mg}$ protein. It accounted for one-third of arginine consumed by fungistatic macrophages. Equimolar amounts of citrulline and total nitrite plus nitrate accumulated in medium. This was consistent with the hypothesis that one of the equivalent guanidino nitrogens of L-arginine was oxidized to both nitrite and nitrate leaving $L$-citrulline as the amino acid reaction product. The analogue, $\mathbf{N}^{\mathbf{G}}$-monomethyl-L-arginine, selectively inhibited nitrogen oxidation and it was shown previously that it inhibited fungistatic capability. Resident macrophages were not fungistatic and their nitrogen oxidation was low. Once macrophages began producing nitrite/nitrate, protein synthesis was not required during the next $8 \mathrm{~h}$ for either fungistasis or nitrogen oxidation. Two-thirds of L-arginine consumption was due to macrophage arginase yielding L-ornithine and urea, which accumulated in medium. This activity was dissociated from macrophage fungistasis. Nitrogen oxidation metabolism by macrophages is linked to a mechanism that inhibits proliferation of fungi. This may involve synthesis of an intermediate compound(s) that has antimicrobial properties. (J. Clin. Invest. 1990. 85:264-273.) arginine $\cdot$ fungistasis $\cdot$ macrophage $\cdot$ microbiostasis $\bullet$ nitrite $\bullet$ nitrate
\end{abstract}

\section{Introduction}

An important aspect of host defense against intracellular microbes is the capability to inhibit microbial replication. Replication is blocked in infections such as tuberculosis, histoplasmosis, and toxoplasmosis, where viable organisms parasitize the tissues for long periods. For some microbes the state of dormancy in host tissues depends upon cell-mediated immune competence. Factors that perturb the poise of the cell-mediated immune response can result in reactivation of dormant microbes leading to clinical infections.

Address reprint requests to Dr. Granger, P.O. Box 2968, Duke University Medical Center, Durham, NC 27710.

Received for publication 20 April 1989 and in revised form 8 August 1989.

J. Clin. Invest.

(c) The American Society for Clinical Investigation, Inc.

0021-9738/90/01/0264/10 \$2.00

Volume 85, January 1990, 264-273
Macrophages are known to be one of the mammalian host's chief instruments for inhibiting microbial replication. They can become repositories of dormant microbes. The physiologic mechanisms that prevent microbial replication within macrophages in infected tissues in vivo are obscure. However in vitro, macrophages can be shown to inhibit division of microbes without killing them, at least for short periods (1-3).

New insight regarding how mouse macrophages block replication of tumor cells comes from the recent discovery that this process depends upon metabolism of L-arginine to nitrite, nitrate, and citrulline $(4,5)$. Nitrite/nitrate synthesis by macrophages is immunologically controlled by the $T$ cell lymphokine, gamma interferon, and it is enhanced by minute amounts of constituents of bacterial cell walls, e.g., endotoxin (6). Nitrite/nitrate synthesis occurs in vivo in mice during mycobacterial infection (7). Inhibition of the facultative intracellular pathogen, Cryptococcus neoformans, by macrophages in vitro depends upon the concentration of L-arginine available, in the extracellular environment, within the physiologic range (8). These findings implicate metabolism of L-arginine by macrophages as a possible biochemical pathway for establishing and maintaining microbial dormancy.

We measured the metabolic fates of $L$-arginine consumed by murine macrophages and correlated these reactions with the functional capability of the phagocytes. Functional capability of macrophages was measured by inhibition of cryptococcal replication. Of four possible pathways of $\mathrm{L}$-arginine utilization, only one consistently correlated with microbiostatic action.

\section{Methods}

Animals. Outbred Swiss-Webster (CD-1) mice (Charles River Laboratories, Research Triangle Park, NC) were used as a source of macrophages. Animals were housed in a separate room, five per cage and fed mouse chow pellets and tap water ad lib.

Media and reagents. All cultures were run in Dulbecco's modified Eagle's medium (DME) prepared from individual constituents in the laboratory. Concentrations of the components were as described (8). These include the following modifications to the published recipe (9): glucose, $25 \mathrm{mM}$; sodium bicarbonate, $24 \mathrm{mM}$; sodium 3- $(N$-morpholino) propanesulfonic acid (MOPS) ${ }^{1}$ buffer, $25 \mathrm{mM}$, pH 7.4; iron as $\mathrm{FeCl}_{3}, 0.25 \mu \mathrm{M}$, prepared from pure iron wire. Vitamins (MEM vitamin solution; Gibco Laboratories, Grand Island, NY) were diluted $1 / 25$ into the final medium. Antibiotics were penicillin G, $100 \mathrm{U} / \mathrm{ml}$ and gentamicin $10 \mu \mathrm{g} / \mathrm{ml}$. The final medium $\mathrm{pH}$ was 7.4 ; phenol red was omitted. The high glucose concentration prevented depletion that could occur due to metabolism by cryptococci and macrophages.

1. Abbreviations used in this paper: CM, cytotoxic macrophages; DFMA, difluoromethyl-L-arginine; MOPS, sodium 3-( $N$-morpholino)propanesulfonic acid; NMA, $\mathbf{N}^{\mathbf{G}}$-monomethyl-L-arginine; rIFN-gamma, recombinant interferon gamma; RM, resident macrophages. 
Phenol red interfered with the colorimetric assay for nitrite. Fetal bovine serum (Hyclone Laboratories, Logan, UT) was dialyzed exhaustively against PBS using 50,000-mol wt cut off tubing (Spectrapor 6; Spectrum Medical Industries, Los Angeles, $\mathrm{CA}$ ), and stored in aliquots at $-85^{\circ} \mathrm{C}$ (D-FBS). Amino acids were from Sigma Chemical Co. (St. Louis, MO). $\mathrm{N}^{\mathrm{G}}$-monomethyl-L-arginine (NMA) was from Calbiochem-Behring Corp., San Diego, CA. Limulus amebocyte lysate assay was from Panmed, Inc. (Three Oaks, MI) and was reconstituted and used according to the supplier.

Microorganisms. Cryptococcus neoformans used in fungistasis assays was a clone (C3D) isolated from a human strain (H99) as described (10). It was designated H99/C3D and its use for measuring CM-mediated fungistasis has been described $(3,11)$. Log phase organisms cultured in DME were washed three times by centrifugation $(4,000 \mathrm{~g})$ and resuspended at a final density of $1 \times 10^{5}$ cells $/ \mathrm{ml}$ in DME for addition to macrophages.

Mycobacterium bovis, strain BCG Phipps (BCG) was obtained from the Trudeau Institute, Saranac Lake, NY, through the courtesy of Donald Auclair. Preparation and storage of Mycobacteria was according to Mackaness et al. (12).

Escherichia coli used in the bioassay for nitrate was a clinical isolate from Duke University Medical Center Clinical Microbiology Laboratories, courtesy of Dr. L. Harrell. This strain was resistant to penicillin at $>1,000 \mathrm{U} / \mathrm{ml}$ and to gentamicin at $>25 \mu \mathrm{g} / \mathrm{ml}$.

Macrophage cultures. Two 2.5 million mouse peritoneal cells were seeded in $1.0 \mathrm{ml}$ DME to a $16-\mathrm{mm}$ culture well (24-cluster plate, Costar, Cambridge, MA). After 45 min nonadherent cells were removed by rinsing three times with PBS and the same process was repeated again to obtain confluent macrophage monolayers. The double seeding procedure was needed to assure complete fungistasis, because cryptococci replicate freely in the microfoci of bare plastic which remain between adherent cells after just one peritoneal cell seeding (11). For complete monolayers of resident macrophages (RM), three such seeding procedures were used. Confluent monolayers may be required because cryptococci may be relatively resistant to macrophage biostatic mechanisms. The relevance of this in vitro system to pathophysiologic events will ultimately require extension to experimental cryptococcosis in vivo.

Cytotoxic macrophages (CM) were from mice injected intraperitoneally 2-5 wk previously with $10^{7}$ colony forming units BCG, and $3 \mathrm{~d}$ before harvest with $1.0 \mathrm{ml} 10 \%$ proteose peptone (Difco, Detroit, MI) Macrophages were cultured in DME containing 10\% D-FBS and 10 $\mathrm{ng} / \mathrm{ml}$ endotoxin (bacterial lipopolysaccharide from $E$. coli $0.128: \mathrm{B} 12$; Sigma Chemical Co., St. Louis, $\mathrm{MO}$ ) at $37^{\circ} \mathrm{C}$ in a humidified $5 \% \mathrm{CO}_{2}$, 95\% air incubator. The macrophage cultures were challenged with cryptococci suspended in DME to give $5 \times 10^{4}$ yeasts $/ \mathrm{ml}$ final density for fungistasis assays, or the cultures overlaid with medium for chemical assays.

Fungistasis assay. Methods were described in detail previously (3, 11). Briefly, after $20 \mathrm{~h}$ co-culture of macrophages with cryptococci, phagocytes were lysed with $0.9 \%$ SDS and cryptococci were killed with $0.5 \%$ sodium hypochlorite before counting electronically $\left(\mathrm{ZB}_{1}\right.$ counter; Coulter Electronics, Hialeah, FL). Macrophage fungistasis was expressed either directly as the number of cryptococci/ml under different conditions, or as the difference between the $\log _{2}$ cryptococci $/ \mathrm{ml}$ in control cultures of fungi alone minus the $\log _{2}$ cryptococci/ml in macrophage-fungi cocultures. This difference is the number of fungal replications inhibited by macrophages per 20-h incubation period (11). All fungistasis cultures were done in two or more replicates and the results shown as the means \pm SEM.

Quantitation of nitrite. Nitrite in DME or macrophage lysates was quantitated colorimetrically after reaction with the Greiss reagents (13). Samples $(0.4 \mathrm{ml})$ were mixed with $0.8 \mathrm{ml} 1 \%$ sulfanilamide- $2.5 \%$ phosphoric acid and $0.8 \mathrm{ml} 0.5 \%$ naphthylethylenediamine dihydrochloride-2.5\% phosphoric acid and absorbance was measured at 543 $\mathrm{nm}$. Concentrations were determined from a linear standard curve between 10 and $200 \mu \mathrm{M}$ sodium nitrite. Assays were done on duplicate or triplicate macrophage cultures. Nitrite production rates were deter- mined per milligram macrophage cell protein using a modified Lowry method (14).

Quantitation of nitrate. Nitrate in DME or macrophage lysates was measured by bioassay using a modification of the method published by Bartholomew (15). Nitrate reductase was induced in $E$. coli by strict anaerobic culture. Then these organisms were used to reduce nitrate to nitrite. Nitrite was measured using the Greiss reagent as described above. The strain of $E$. coli used is described above under Microorganisms. An antibiotic resistant strain was used to obviate the potential effects of antibiotics in DME on bacterial metabolism of nitrate. Log phase $E$. coli in $5.0 \mathrm{ml}$ trypticase soy broth were seeded into flasks containing 1.0 liter of the nitrate reductase-inducing medium described in $(15,16)$. The flasks had been incubated for $2 \mathrm{~d}$ at $25^{\circ} \mathrm{C}$ in an anaerobic chamber (courtesy of Dr. Gale Hill, Clinical Microbiology Laboratory, Duke Medical Center) to remove oxygen. The oxygen concentration of the chamber was $<25 \mathrm{ppm}$ as measured by continuous oxygen monitoring. After inoculation the flasks were incubated in the anaerobic chamber at $37^{\circ} \mathrm{C}$ with stirring for $18 \mathrm{~h}$. Bacteria were harvested and washed by centrifugation $(6,000 \mathrm{~g})$ three times using PBS. The wet cell pack weight was determined in a tared vessel and a suspension of $1.0 \mathrm{~g}$ cells per $10 \mathrm{ml}$ PBS was made. Aliquots were stored frozen at $-85^{\circ} \mathrm{C}$. Samples of the final bacterial suspension were cultured aerobically on chocolate agar and Sabouraud's agar and anaerobically on blood agar plates to assure that a pure culture was obtained. For nitrate assay a $0.3-\mathrm{ml} \mathrm{sample} \mathrm{was} \mathrm{incubated} \mathrm{at} 37^{\circ} \mathrm{C}$ for $90 \mathrm{~min}$ with $0.15 \mathrm{ml}$ substrate (formate buffer containing $2.0 \mathrm{M}$ ammonium formate; $1.0 \mathrm{M} \mathrm{NaPi}, \mathrm{pH} \mathrm{7.3)}$ and $0.15 \mathrm{ml}$ of a $1 / 10$ dilution in PBS of the stock $E$. coli suspension. Each lot of bacterial suspension was titrated for complete reduction of $1.0 \mathrm{mM} \mathrm{NaNO}_{3}$ standard in $90 \mathrm{~min}$ at $37^{\circ} \mathrm{C}$. For all lots of $E$. coli suspension prepared, complete reduction was obtained at a 1/64 dilution or greater of the stock $E$. coli suspension. This assured that all nitrate produced by macrophages was detected by the bioassay. After incubation the mixtures were microfuged for 2.0 min (microfuge B; Beckman Instruments, Inc., Palo Alto, CA) to pellet bacteria and $0.4 \mathrm{ml}$ supernatant sample was assayed for nitrite using the procedure described above. Nitrate concentration was determined from the difference between total nitrite concentration after bacterial reduction and nitrite concentration before bacterial reduction. A series of nitrate standards $\left.(0-200 \mu \mathrm{M} \mathrm{NaNO})_{3}\right)$ reduced and assayed for nitrite closely agreed with a series of nitrite standards $(0-200 \mu \mathrm{M})$ prepared from reagent $\mathrm{NaNO}_{2}$. This demonstrated that bacteria did not reduce nitrite further to ammonia under the conditions of the assay. Nitrate production by macrophages was determined on triplicate cultures per time point and expressed per milligram cell protein as above.

Analysis of amino acid metabolites. Culture medium samples or macrophage cell lysates were microfuged for $2 \mathrm{~min}$ and supernatants were stored frozen until analysis. Radiolabeled $\mathrm{L}$-arginine and its metabolites were separated by reversed-phase ionpairing HPLC on a 3.9 $\mathrm{mm} \times 15 \mathrm{~cm} \mathrm{C}_{18}$ micro-Bondapak column (Waters Associates, Milford, MA) using a modification of the method in (17). Isocratic mobile phase was $10 \%$ methanol: $90 \%$ aqueous sodium acetate $(25 \mathrm{mM}, \mathrm{pH}$ 4.35)-sodium hexanesulfonate $(15 \mathrm{mM})$ run at $0.8 \mathrm{ml} / \mathrm{min}$. Standards were detected spectrophotometrically at $214 \mathrm{~nm} .{ }^{14} \mathrm{C}$-labeled compounds were measured by liquid scintillation spectrometry on 0.4-ml fractions from the column emulsified into $5.0 \mathrm{ml}$ Biofluor (New England Nuclear, Boston, MA). Medium for these assays was the same as in the furgistasis assay except that ${ }^{14} \mathrm{C}$-labeled $\mathrm{L}$-arginine was added. Stoichiometric data was calculated from disintegrations per minute obtained by the external standard ratio correction method. Water and reagents for chromatography were all HPLC grade.

Quantitation of $\left[{ }^{14} \mathrm{C}\right]$ urea. Radioactive urea formed from ${ }^{14} \mathrm{C}$-labeled $\mathrm{L}$-arginine was measured by treating samples with urease and trapping evolved $\left[{ }^{14} \mathrm{C}\right] \mathrm{CO}_{2}$ (18). The reaction flasks (10 ml; Kontes Glassware, Vineland, $\mathrm{NJ}$ ) were sealed with rubber stoppers equipped with plastic cups containing $0.1 \mathrm{ml}$ Protosol (New England Nuclear). $25-\mu 1$ samples were added to $1.0 \mathrm{ml} 0.2 \mathrm{M} \mathrm{KPi}, \mathrm{pH} 6.3$. After sealing the flasks, $0.1 \mathrm{ml}$ urease (Sigma; type C-3, $50 \mathrm{mg} / \mathrm{ml}$ water) was in- 
jected through a stoppered side arm and the flasks were incubated at $35^{\circ} \mathrm{C}$ on a New Brunswick shaker with gentle swirling for $30 \mathrm{~min}$. The cups were cut into $20-\mathrm{ml}$ scintillation vials and counted using a cocktail of Econofluor (New England Nuclear) with $10 \%$ methanol. The efficiency of trapping was measured using $\left[{ }^{14} \mathrm{C}\right]$ urea (Amersham; 58 $\mathrm{mCl} / \mathrm{mmol} \mathrm{sp}$ act) and was consistently $90 \%$ (mean \pm SEM $=89.5 \% \pm 0.8 ; n=15$ experiments). The disintegrations per minute unaccounted for were not present in the reaction medium. Urea values were corrected by multiplying by 1.12 to account for the consistent error of $90 \%$ trapping efficiency.

Arginine decarboxylase activity. Evolution of $\left[{ }^{14} \mathrm{C}\right] \mathrm{CO}_{2}$ from carboxyl-labeled arginine was used to measure arginine decarboxylase activity. Acid cleaned $\mathrm{CO}_{2}$ trapping flasks $(10 \mathrm{ml})$ were used for macrophage culture by the usual method. Each flask received $12 \times 10^{6}$ peritoneal exudate cells. After removing nonadherent cells, $3.0 \mathrm{ml}$ culture medium was added, the flasks were stoppered with the plastic cups in place, and incubated at $37^{\circ} \mathrm{C}$. Medium was DME but without sodium bicarbonate. $\mathrm{L}$-arginine concentration was $0.5 \mathrm{mM}$ including $46 \mathrm{nCi} / \mathrm{ml}$ D,L-carboxyl $\left[{ }^{14} \mathrm{C}\right]$ arginine $(46 \mathrm{mCi} / \mathrm{mmol}$ sp act; Research Products, Inc., Mt. Prospect, IL). After a given incubation $0.15 \mathrm{ml}$ protosol was injected through the sidearm stopper into the cups and the flasks were rotated for $15 \mathrm{~min}$ to trap carbon dioxide. Then the cups were cut into vials and counted in $15 \mathrm{ml}$ Econofluor-methanol cocktail. The amount of arginine converted to labeled carbon dioxide was calculated taking into consideration that the disintegrations in carboxyl labeled D-arginine (50\%) was unavailable for metabolism.

Incorporation of ${ }^{14} \mathrm{C}$-amino acids into macrophages. Macrophage cultures, which had been preincubated overnight in DME containing murine rINF gamma, $100 \mathrm{U} / \mathrm{ml}$, to induce nitrite/nitrate production, were washed and overlaid with DME containing $0.2 \mu \mathrm{Ci} / \mathrm{ml} \mathrm{U}-\left[{ }^{14} \mathrm{C}\right]$ L-amino acid mixture $(50 \mathrm{mCi} / \mathrm{mmol} \mathrm{sp}$ act; ICN, Irvine, CA). After incubation the cells were washed three times with PBS to remove extracellular amino acids and then they were incubated for $30 \mathrm{~min}$ in amino acid-free DME to deplete intracellular amino acid pools. After washing the macrophages again three times with PBS the cells were dissolved by adding $1.0 \mathrm{ml}$ of $1 \% \mathrm{SDS}$, then ${ }^{14} \mathrm{C}$ in the lysates was counted in Biofluor.

The assay estimated new incorporation of amino acids into protein because $5.0 \mu \mathrm{M}$ puromycin or $1.0 \mu \mathrm{M}$ cycloheximide completely blocked incorporation of ${ }^{14} \mathrm{C}$-amino acids into the macrophages beyond a low level incorporation, occurring during the first $30 \mathrm{~min}$ of labeling. This method obviated the variability inherent in attempting quantitative recoveries of acid precipitates from the highly adherent macrophages, which could only be removed from plastic by mechanical scraping.

\section{Results}

Conversion of L-arginine to ornithine and urea. Both $\mathrm{CM}$ and RM consumed L-arginine from DME as measured by progressive diminution of the radioactive arginine peak of chromatographed medium. The results of 12 experiments (Table I) showed higher arginine consumption by CM compared to RM. The major products of arginine metabolism were ornithine and urea, which accumulated in the medium in equimolar amounts (Table I). This activity has been reported from murine macrophages and is due to secreted arginase (19). In the case where $\left[{ }^{14} \mathrm{C}\right]$ carboxyl-labeled $\mathrm{D}, \mathrm{L}$-arginine was used as the tracer, no radioactive carbon dioxide was detected upon treatment of the medium sample with urease (Table I). This finding was consistent with the absence of radioactivity in arginine carbon- 6 , the precursor of carbon dioxide in urea derived from arginine upon treatment with arginase. Conversely, when L-arginine labeled exclusively at carbon-6 $\left({ }^{14} \mathrm{C}\right.$-guanido-L-arginine) was added to $\mathrm{CM}$ and $\mathrm{RM}$ cultures, radioactive carbon dioxide was trapped from medium samples treated with urease. The molar amount produced very nearly equalled the molar amount of ornithine measured by HPLC (Table I). These results and those from experiments employing ${ }^{14} \mathrm{C}$-universally labeled $L$-arginine are consistent with an activity attributable to macrophage-derived arginase (Table I).

It was shown previously that $N^{G}$-monomethyl-L-arginine (NMA) inhibited L-arginine-dependent fungistasis (8). Hence the effect of NMA on CM arginase activity was examined (Table I). It was clear that NMA did not inhibit arginase activity. On the contrary, a larger fraction of arginine was metabolized to ornithine and urea.

Macrophage arginase activity (Table I) did not correlate with macrophage fungistatic capability. Arginase activity (micromoles urea or ornithine per $20 \mathrm{~h}$ per $\mathrm{mg}$ macrophage protein) was present in both $\mathrm{RM}$ and $\mathrm{CM}$ treated with $50 \mu \mathrm{M}$ NMA. These conditions never yielded fungistasis $(3,8)$. Both

Table I. Macrophage Metabolism of Arginine to its Major Products

\begin{tabular}{|c|c|c|c|c|c|c|c|c|}
\hline \multirow[b]{3}{*}{$\mathbf{M} \phi^{*}$} & \multirow{3}{*}{$\begin{array}{c}\text { No. of } \\
\text { experiments }\end{array}$} & \multirow[b]{3}{*}[{}^{14}\mathrm{C}]{$\mathrm{Arg}^{*}$} & \multirow[b]{3}{*}{ NMA $^{3}$} & \multirow{3}{*}{$\frac{\begin{array}{c}\text { Substrate } \\
\text { consumed }\end{array}}{\text { L-Arg" }}$} & \multicolumn{4}{|c|}{ Metabolites produced via: } \\
\hline & & & & & \multicolumn{2}{|c|}{ Arginase" } & \multicolumn{2}{|c|}{ Nitrogen oxidation" } \\
\hline & & & & & Orn & Urea & Cit & $\mathrm{NO}_{2}^{-}+\mathrm{NO}_{3}^{-}$ \\
\hline $\mathrm{CM}$ & 5 & $\mathbf{u}$ & - & $5.70 \pm 0.46$ & $4.06 \pm 0.20$ & $4.02 \pm 0.26$ & $1.62 \pm 0.26$ & $1.62 \pm 0.14$ \\
\hline $\mathrm{CM}$ & 1 & g & - & 4.82 & 3.20 & 3.24 & 1.66 & 1.68 \\
\hline $\mathrm{CM}$ & 1 & c & - & 6.44 & 4.60 & 1 & 1.86 & 1.98 \\
\hline $\mathrm{CM}$ & 1 & $\mathbf{u}$ & + & 6.24 & 5.86 & 5.94 & 0.42 & 0.32 \\
\hline $\mathrm{CM}$ & 1 & c & + & 6.92 & 6.08 & I & 0.44 & 0.44 \\
\hline RM & 1 & $\mathbf{u}$ & - & 4.90 & 4.40 & 4.50 & 0.38 & 0.50 \\
\hline $\mathrm{RM}^{* *}$ & 1 & g & - & 2.26 & 2.26 & 2.20 & 0.14 & 0.24 \\
\hline $\mathbf{R M}^{* *}$ & 1 & c & - & 1.00 & 0.98 & $\checkmark$ & 0.06 & 0.04 \\
\hline
\end{tabular}

* All macrophages cultured in $10 \mathrm{ng} / \mathrm{ml}$ endotoxin unless specified otherwise. ${ }^{\ddagger 14} \mathrm{C}$-labeled L-arginine; $\mathrm{u}$, universally labeled L-arginine; $\mathrm{g}$, guanido-labeled L-arginine; c, carboxyl-labeled D,L-arginine. ${ }^{8} \mathrm{NMA}, 50 \mu \mathrm{M}$. "Values are total micromoles consumed or produced based on concentrations in medium at $20 \mathrm{~h}$. Data normalized by expressing results as amounts per milligram macrophage protein. Cell proteins ranged from $0.034-0.090 \mathrm{mg}$ for $\mathrm{CM}$ and $0.028-0.055 \mathrm{mg}$ for RM. Values in first line compiled from five experiments are means \pm SEM. 'Background counts for ${ }^{14} \mathrm{CO}_{2}$ trapped. ${ }^{* *}$ No endotoxin present. 
urea and ornithine singly or in combination at the concentrations present in medium over macrophages had no fungistatic activity when they were added to medium plus cryptococci alone.

L-arginine depletion by arginase could readily occur in cell culture medium where the concentration is $400 \mathrm{nmol} / \mathrm{ml}$ (e.g., commercial DME). In macrophage-tumor cell co-cultures arginine depletion was reported to inhibit tumor cell proliferation due to starvation for this amino acid (20). However, arginine depletion did not account for macrophage fungistasis because replication of cryptococci was not dependent on L-arginine (8). Depletion of L-arginine could inhibit macrophage-mediated fungistasis because macrophages required this amino acid to produce effector molecules (8).

Arginase was found in conditioned medium over macrophages. Also the enzyme was present in macrophage lysates. A small arginase activity was present in commercial fetal bovine serum used in cytotoxicity experiments $(5.0 \mathrm{nmol}$ urea or ornithine/h per $\mathrm{ml}$ at $25 \%$ serum in DME containing $500 \mu \mathrm{M}$ L-arginine).

Conversion of L-arginine to citrulline, nitrite, and nitrate. A substantial quantity of L-arginine consumed by $\mathrm{CM}$ was converted to a radioactive product that by HPLC had a retention time identical to L-citrulline (Table I). This product was present in culture medium over CM irrespective of whether the ${ }^{14} \mathrm{C}$ was carboxyl, guanido, or throughout the arginine molecule. This would be consistent with a product containing all six of the carbon atoms present in the original arginine. The product was excluded from the HPLC $\mathrm{C}_{18}$ column indicating loss of ion pairing capability. This suggested loss of the positively charged guanidino nitrogen of arginine.

The guanidino nitrogen of $\mathrm{L}$-arginine was accounted for as measurable nitrite and nitrate anions (Table I). Under all the conditions shown in Table I, the total molar amount of nitrite and nitrate, measured by biocolorimetric assay, closely approximated the molar amount of citrulline, measured by HPLC, in a 1:1 stoichiometry. These findings point to a second major pathway of arginine utilization in which macrophages oxidized the guanidino nitrogen of L-arginine to nitrite and nitrate leaving citrulline as the deiminated carbamido reaction product. This finding was reported by Hibbs et al. using a colorimetric assay to detect citrulline $(4,5)$. Iyengar et al. showed the same metabolism by a macrophage cell line activated with rINF-gamma (21). However, the continuous macrophage cell line produced more citrulline than $\mathrm{NO}_{2}^{-} / \mathrm{NO}_{3}^{-}$due to conversion of ornithine (derived from arginine via arginase activity) to citrulline by the cells (21). This second pathway, that of $L$-arginine nitrogen oxidation, accounted for $\sim 30 \%$ of arginine consumption by CM (Table I). Nitrogen oxidation by $\mathrm{CM}$ was inhibited by 75\% when NMA was added at a ratio of 1 NMA: 10 arginines. For RM, nitrogen oxidation was undetectable or occurred at low levels.

The nitrite, nitrate, and citrulline produced by $\mathrm{CM}$ was almost exclusively extracellular; lysates of CM did not contain appreciable amounts of these products. Unlike arginase secreted by macrophages, conditioned cell-free supernates from CM cultures were devoid of nitrogen oxidation activity.

Correlation between nitrogen oxidation and fungistasis by macrophages. Four types of experiments showed the correlation between nitrogen oxidation and fungistatic capability. First was the dependence on L-arginine for both processes. Nitrite and nitrate production rates in the absence of extracel- lular L-arginine were measurable but low (Fig. 1). This correlated with the complete failure of macrophage fungistasis under these conditions (8). With $500 \mu \mathrm{M}$ L-arginine present, production of both nitrite and nitrate increased markedly (Fig. 1 ), and it was during this time, under these conditions, that fungal replication ceased (8). In Fig. 1 the proportion of nitrite and nitrate produced was approximately equal. However, this was not always the case. The ratio of nitrite/nitrate produced by $C M$ varied between $1: 1$ and $2: 1$.

When the L-arginine concentration was varied between 0 and $500 \mu \mathrm{M}$ a graded effect on macrophage fungistasis was seen (Fig. $2 A$ ). Over this same concentration range, under the same conditions of macrophage-cryptococci cocultures, a graded response of nitrite production occurred (Fig. $2 \mathrm{~B}$ ). Control cultures of cryptococci alone showed that the fungi neither produced (Fig. 2) nor consumed (not shown) nitrite or nitrate.

The kinetics of nitrite production by activated macrophages at varying L-arginine concentration is shown in Fig. 3. At zero extracellular L-arginine a low but measurable production occurred. This rate was higher than the rate at zero arginine in Fig. 2. This may be explained by the effect of preincubation in arginine-containing DME for $16 \mathrm{~h}$ before the rate measurements (Fig. 3, legend). Thus CM may have accumulated a significant endogenous arginine pool, which could serve as substrate for nitrite synthesis. Lineweaver-Burk transformation of this data showed correlation between the rate of nitrite production and arginine concentration $(r=0.93)$. Maximal velocity of synthesis was $67 \mathrm{nmol} / \mathrm{h}$ per $\mathrm{mg}$ cell protein. From the results shown in Fig. $2 A$ it appeared that maximal nitrite production correlated with complete fungistasis. The concentration of L-arginine giving one-half $V_{\max }\left(K_{\mathrm{m}}\right)$ equaled $73 \mu \mathrm{M}$. This may be an important value because the level of arginine in plasma of various mammals is $\sim 100 \mu \mathrm{M}$ (22). This presents the possibility of controlling the rate of nitrite synthesis of macrophages by regulating plasma amino acid concentration.

In the second type of correlation experiment activated macrophage fungistasis was blocked with the specific inhibitor,

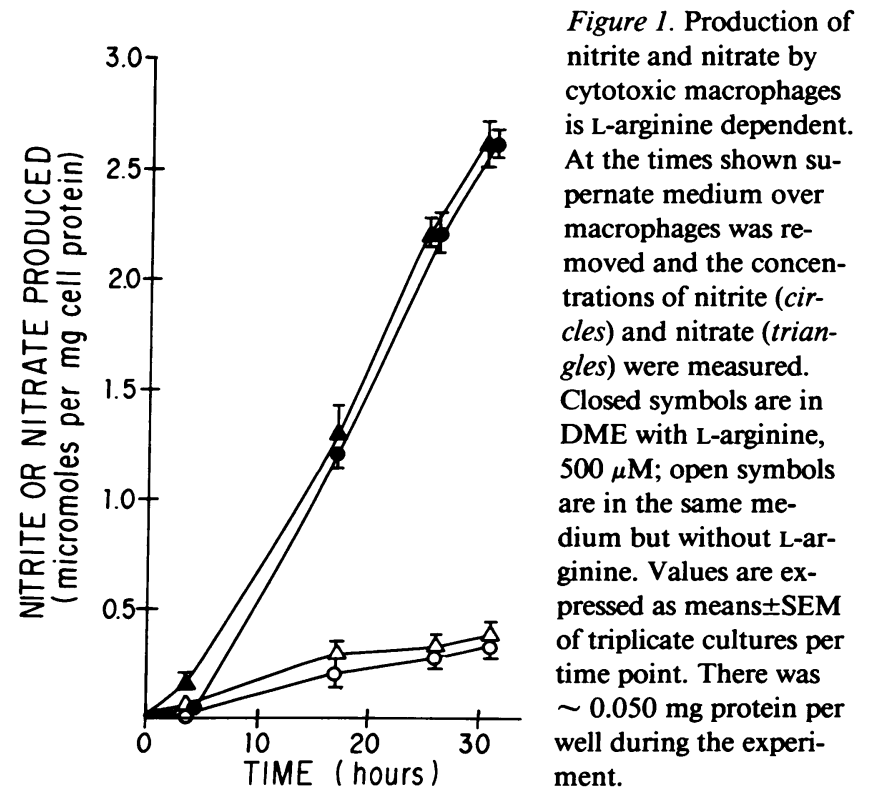



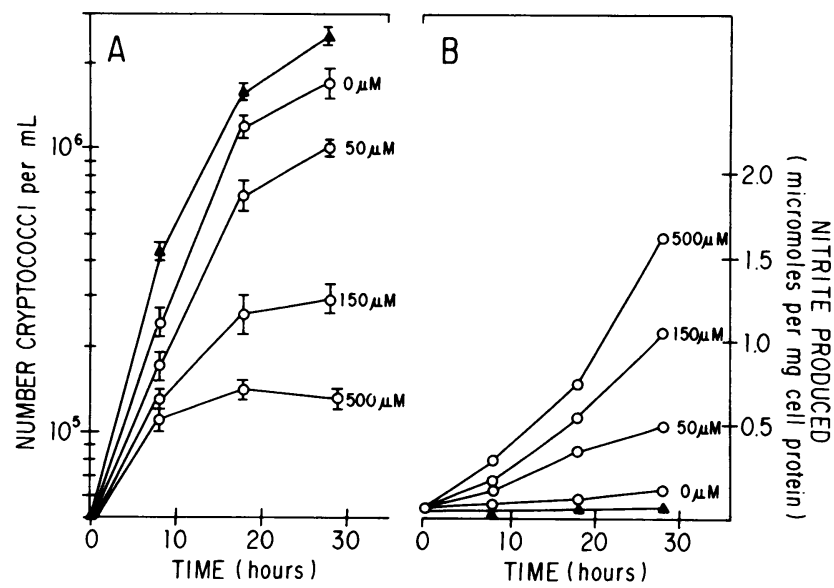

Figure 2. Correlation between L-arginine-dependent fungistasis and nitrite production by cytotoxic macrophages. Macrophage-cryptococci co-cultures (open circles) incubated in DME + 10\% D-FBS and endotoxin at the $\mathrm{L}$-arginine concentrations shown were assayed for fungistasis $(A)$ or supernate nitrite concentration $(B)$. Protein content per well $(\sim 0.038 \mathrm{mg})$ was measured on parallel macrophage alone cultures. Closed triangles are for cryptococci alone cultures. Values are means $\pm \operatorname{SEM}(A)$ of triplicate cultures.

NMA (8). Under these conditions citrulline, nitrite, and nitrate synthesis was markedly inhibited at each time measured during a 28-h assay (Fig. $4 \mathrm{~B}$ ) compared to $\mathrm{CM}$ cultures without NMA (Fig. $4 A$ ). N $^{\mathrm{G}}$-Monomethyl-L-arginine was not toxic for macrophages. Inhibition of macrophage fungistasis was completely reversible by removing NMA by washing (8).

The third type of experiment took advantage of the previous finding that mouse resident peritoneal macrophages were never fungistatic (3). In Fig. 4, $C$ and $D$ metabolite syn-

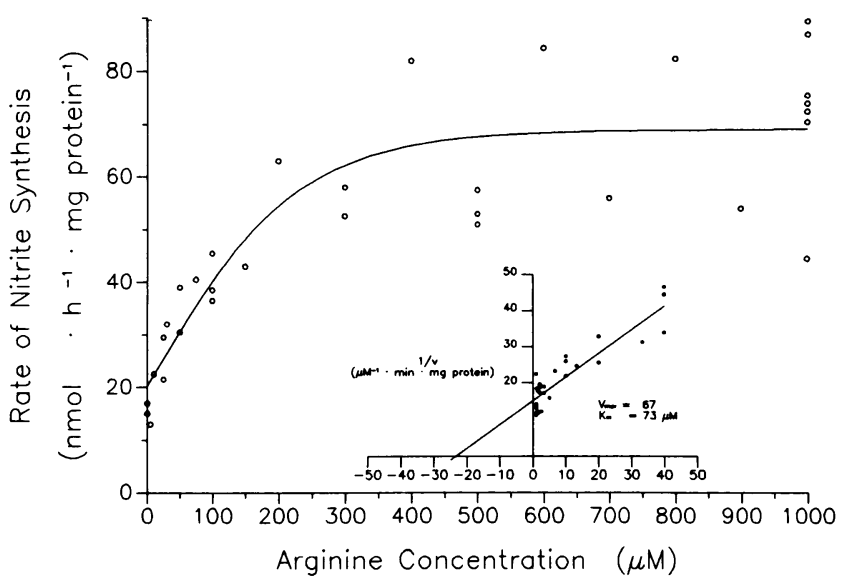

Figure 3. Rate of nitrite production by cytotoxic macrophages versus $\mathrm{L}$-arginine concentration. CM were pre-incubated for $16 \mathrm{~h}$ in DME containing $500 \mu \mathrm{M}$ L-arginine + endotoxin, $100 \mathrm{ng} / \mathrm{ml}$. Then the macrophages were washed three times with PBS and recultured in $\mathrm{DME}$ at the L-arginine concentrations shown. Duplicate medium supernate nitrites were measured hourly for $4 \mathrm{~h}$. This gave linear synthesis rates that were expressed per milligram macrophage protein (open circles). Results are from 9 separate experiments. Average protein concentration was $0.052 \mathrm{mg} /$ well (range $=0.034-0.069$ ). Double reciprocal plot of data shown as inset (closed circles). $V_{\max }=1 / y$-intercept; $K_{\mathrm{m}}=($ slope $)\left(V_{\max }\right)$. Correlation coefficient for linear regression was $r=0.93$.

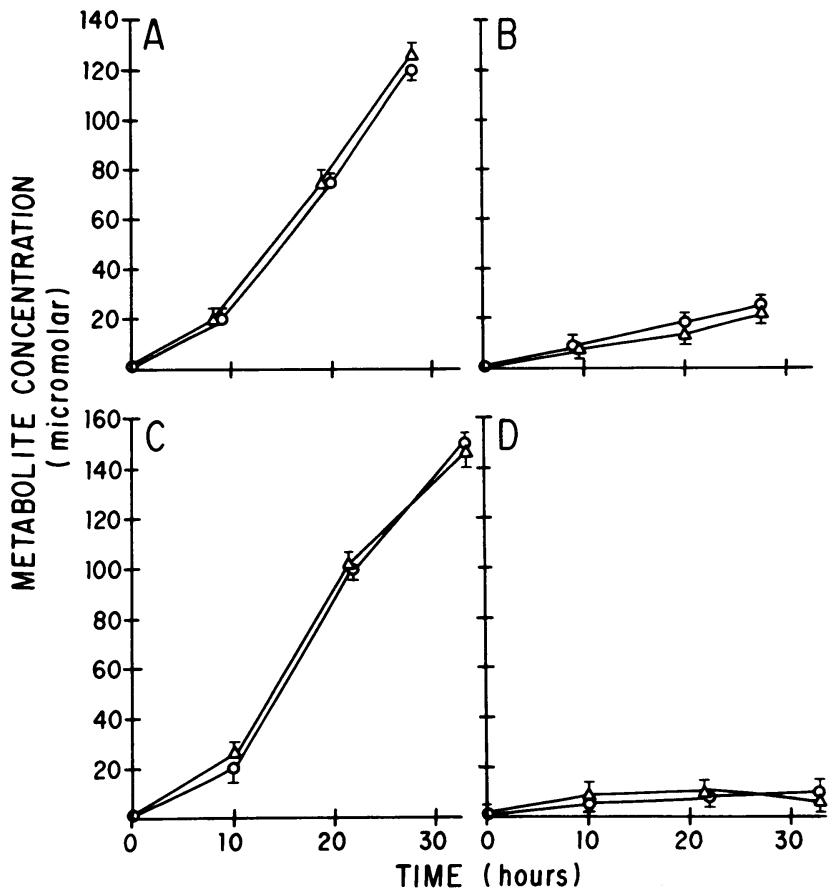

Figure 4. Production of citrulline, nitrite and nitrate by macrophages. CM $(A, B$, and $C)$ or RM $(D)$ were cultured in DME containing $100 \mathrm{ng} / \mathrm{ml}$ endotoxin and $500 \mathrm{nCi} / \mathrm{ml} \mathrm{U}-\left[{ }^{14} \mathrm{C}\right]$ arginine. Medium in B contained $50 \mu \mathrm{M} \mathrm{N} \mathrm{N}^{\mathrm{G}}$-monomethyl-L-arginine. At the times shown supernate medium was collected for measurement of the total $\mathrm{NO}_{2}^{-}+\mathrm{NO}_{3}^{-}$(triangles) and radioactive citrulline (circles). Values are means \pm SEM of triplicate cultures per time point. Macrophage protein per well was $0.060 \mathrm{mg},(A) ; 0.057 \mathrm{mg},(B) ; 0.075 \mathrm{mg}$, (C); and $0.055 \mathrm{mg},(D)$.

thesis during $30 \mathrm{~h}$ culture is shown for a representative experiment comparing CM and RM. Resident macrophages produced almost no citrulline, nitrite, or nitrate, while CM produced these metabolites at a maximal rate between 10 and 30 h incubation. As shown in Fig. 4, $A$ and $C$, accumulation of L-citrulline and the total nitrite plus nitrate occurred in equimolar amounts in unison.

The fourth type of experiment involved the induction of nitrite production and the induction of fungistasis by CM (Fig. $5)$. When these two activities were measured together it was clear that they were correlated. A lag phase before the onset of fungistasis was observed in our original studies (3) and was repeatedly observed thereafter $(8,11)$. This is shown in a representative experiment in Fig. $5 \mathrm{~A}$. In the same experiment medium nitrite concentration was measured hourly (Fig. $5 \mathrm{~B}$ ). There was a 3-4-h lag phase before nitrite synthesis commenced, and this closely coincided with the onset of fungistasis which was first detected at $6 \mathrm{~h}$. The lag phase for nitrite production was also very consistent. It is not clear why explantation of CM into culture resulted in a window of time during which nitrite synthesis was absent. This is assuming that these same macrophages were synthesizing nitrite/nitrate in vivo, an assumption for which there is experimental evidence based on urinary nitrate excretion in mice infected with BCG by intraperitoneal injection (7).

When reagent nitrite, nitrate, or the combination of nitrite + nitrate was added to DME in the concentration range mea- 

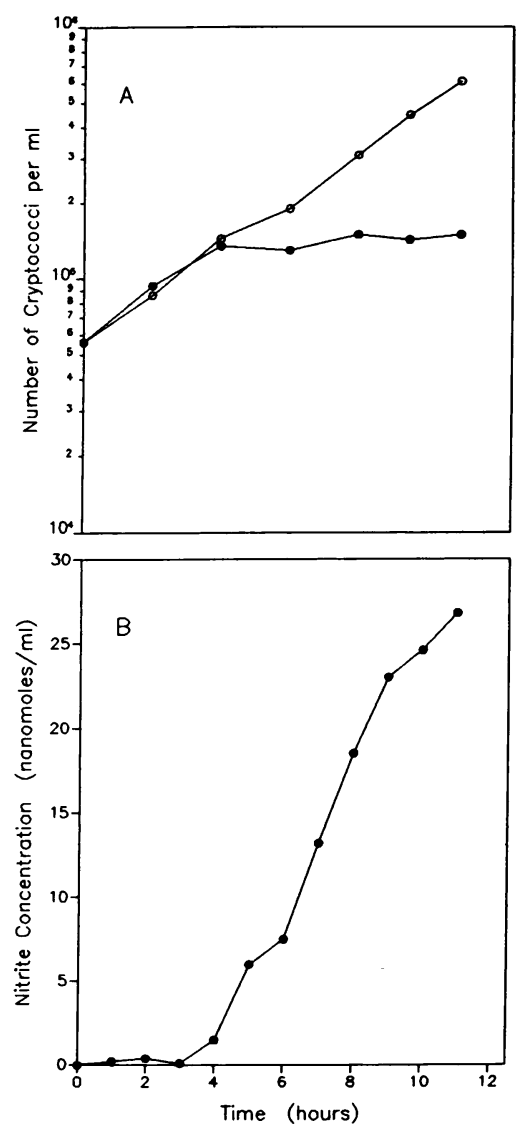

Figure 5. Onset of macrophage fungistasis coincides with onset of nitrite production. $\mathrm{CM}$ were cultured in DME containing 10\% D-FBS, and endotoxin, 100 $\mathrm{ng} / \mathrm{ml}$, and $5.6 \times 10^{4} C$. neoformans (closed circles). At the intervals shown fungal cell counts $(A)$ or supernate nitrate concentrations $(B)$ were determined. Open circles are fungi alone cultures $(A)$. Cryptococci alone did not produce nitrite (not shown). Values are the means of duplicate cultures. Macrophage protein content per well was $0.058 \mathrm{mg}$.

sured from CM cultures, no fungistatic effect was produced. This was also the case for the hypothetical intermediates, ammonium ion, and hydroxylamine. Whether oxides of nitrogen such as nitric oxide or nitrogen dioxide inhibit cryptococcal replication is currently being investigated.

The effect of D-FBS on CM production of nitrite/nitrate was tested because serum was shown to be an important requirement for fungistasis (11). The rate at which $\mathrm{CM}$ produce both nitrite and nitrate was the same with and without D-FBS. In some experiments the lag period to the onset of macrophage nitrite synthesis was delayed 1-2 $h$ when D-FBS was absent, but this was not always the case. We concluded that the serum requirement for fungistasis by $\mathrm{CM}$ was for some other macrophage function not directly related to nitrogen oxidation metabolism.

L-arginine utilization for protein synthesis is not required for fungistasis. Protein molecules possessing fungicidal properties are synthesized by leukocytes, including macrophages (23). Some of these proteins are cationic at neutral $\mathrm{pH}$, in part because they are rich in arginine residues (24). Because fungistasis depended upon medium L-arginine, the utilization of this amino acid and the other essential amino acids for protein synthesis was measured in relation to both nitrite synthesis and fungistasis to examine for correlation or lack of correlation between these activities. Our intent was to construct culture conditions in which protein synthesis was blocked, but nitrite production was not, and then measure fungistatic capability of the macrophages.

If the inhibitors of protein synthesis, (cycloheximide, 0.5 $\mu \mathrm{M}$, or puromycin $5.0 \mu \mathrm{M}$ ), or of transcription (actinomycin
$\mathrm{D}, 0.1 \mu \mathrm{M})$ were added to freshly explanted CM cultured in medium with endotoxin, nitrite, and nitrate production was markedly reduced. Furthermore, each inhibitor was toxic to macrophages in the presence of endotoxin after $\sim 10 \mathrm{~h}$ incubation. Since nitrite/nitrate synthesis began only after a substantial lag period (Fig. $5 \mathrm{~B}$ ), it was possible that the inhibitors blocked synthesis of the enzyme(s) required for nitrogen oxidation.

We searched for conditions where protein synthesis could be blocked after the induction of high level nitrite production, and where the inhibitors were not toxic to the macrophages during a time-frame when fungistasis could be tested. A protocol was devised in which murine rINF gamma, $100 \mathrm{U} / \mathrm{ml}$, was used in an overnight incubation of BCG/peptone macrophages. By the following morning these macrophages, cultured in endotoxin-free medium, actively synthesized nitrite for the ensuing $8 \mathrm{~h}$ without a lag period, and puromycin (Fig. $6 \mathrm{~A}$ ) or cycloheximide, $0.5 \mu \mathrm{M}$, (not shown) did not affect nitrite production. However, puromycin (Fig. $6 \mathrm{~B}$ ) and cycloheximide (not shown) completely blocked incorporation of ${ }^{14} \mathrm{C}$-labeled amino acids by the same macrophages between 2 and $8 \mathrm{~h}$ incubation. When macrophage fungistasis was measured under these conditions using puromycin as the inhibitor of protein synthesis, a clear result was obtained. Unlike cycloheximide, puromycin did not affect fungal replication, thus it was an ideal inhibitor for use in the macrophage fungistasis assay (Fig. $6 \mathrm{C}$ ). Macrophage-induced fungistasis occurred whether or not puromycin was present. Thus, macrophages are fully capable of inhibiting fungal proliferation during hours 2 through 8 despite a complete block of new amino acid incorporation. Beyond $8 \mathrm{~h}$ the inhibitors were eventually toxic for macrophages.

The potential pitfall of this type of experiment was the possibility that macrophage fungistasis in the presence of puromycin was due to preformed arginine-containing defensins synthesized and stored before addition of the inhibitor. To test this possibility, the requirement for arginine in puromycin-in-
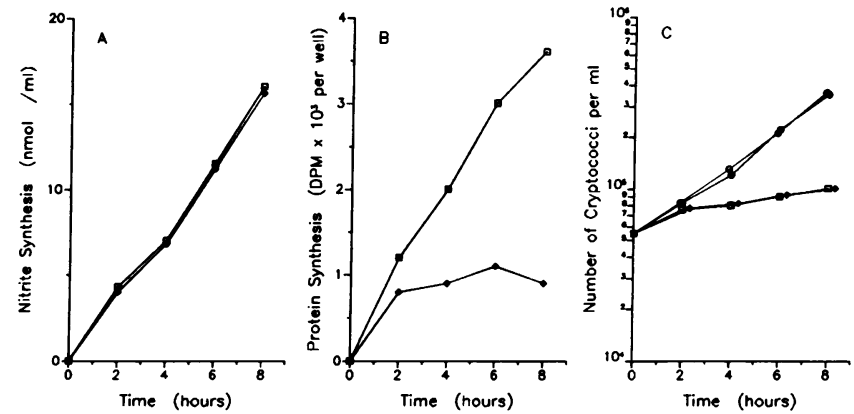

Figure 6. Effect of inhibiting macrophage protein synthesis on fungistasis and nitrite production. CM were cultured overnight in DME containing murine rINF gamma, $100 \mathrm{U} / \mathrm{ml}$. Then macrophages were washed and recultured in the same medium containing $10 \%$ D-FBS and ${ }^{14} \mathrm{C}$-amino acids, with (closed diamonds) or without (open squares) $5.0 \mu \mathrm{M}$ puromycin. At the times shown supernate nitrite concentration $(A)$ and incorporated ${ }^{14} \mathrm{C}$-amino acids $(B)$ were measured. In $\mathrm{C}$ parallel $\mathrm{CM}$ cultures were challenged with $C$. neoformans to assess CM fungistatic capability (open squares = without puromycin; closed diamonds = with puromycin). Circles are fungi alone cultures with (closed) or without (open) puromycin. Values are means of duplicate cultures. Macrophage protein per well was $0.041 \mathrm{mg}$. 
hibited macrophages was examined. With puromycin present nitrite production was, as without puromycin, largely dependent on medium L-arginine (Fig. $7 A$ ). The same was true for fungistasis (Fig. $7 \mathrm{~B}$ ). Under conditions where puromycin inhibited new protein synthesis, macrophages nevertheless, remained dependent on medium L-arginine to effectively block fungal proliferation. Thus, these experiments provided evidence that the L-arginine requirement for macrophage fungistasis included a process in addition to utilization of arginine for macrophage protein synthesis. Furthermore, the L-arginine-dependent process, as before, correlated with nitrite production. Because efficient macrophage fungistasis occurred under conditions where protein synthesis was blocked, yet still depended upon an external source of $\mathrm{L}$-arginine, it seemed unlikely that the mechanism of fungistasis involved synthesis and release of cytotoxic proteins known to kill cryptococci, i.e., defensins.

Is macrophage decarboxylation of L-arginine involved in fungistasis? Biosynthesis of polyamines from L-arginine or Lornithine is important for regulating cell proliferation in many types of animal cells (25). In addition, oxidation of the polyamines, spermine, or spermidine by polyamine oxidase leads to aminoaldehyde products that possess anti-protozoal activity (26). The initial step in polyamine biosynthesis involves decarboxylation of L-ornithine (in mammals) or L-arginine (in protozoa), yielding putrescine $+\mathrm{CO}_{2}$ and agmatine $+\mathrm{CO}_{2}$, respectively. It was possible that the L-arginine requirement for macrophage fungistasis involved polyamine synthesis, either by arginine decarboxylation or by L-arginine conversion to L-ornithine by macrophage arginase and then ornithine decarboxylation. To examine this point carboxyl ${ }^{14} \mathrm{C}$-labeled L-arginine and L-ornithine were used as substrates for macrophages and radioactive carbon dioxide was trapped and quantitated under conditions of varying fungistatic capability. A small flux of carboxyl-labeled arginine ended up as radioactive carbon dioxide (Table II). This accounted for less than $1.0 \%$ of arginine metabolism by activated macrophages (compare Tables I
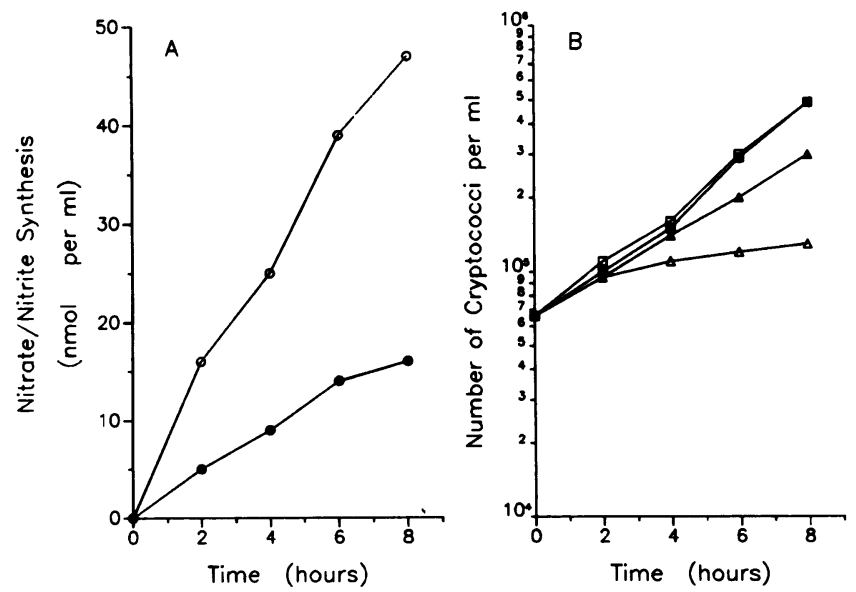

Figure 7. L-arginine is required for fungistasis by puromycin-treated CM. Experimental protocol was the same as in Fig. 6. All CM cultures received $5.0 \mu \mathrm{M}$ puromycin. Open symbols are complete medium; closed symbols are for medium lacking only L-arginine. In $A$ supernates were assayed for total nitrite + nitrate. In $B$ cryptococci per $\mathrm{ml}$ were counted for fungi alone cultures (squares) and CM + fungi cocultures (triangles). Values are means for duplicate cultures at each time point. Macrophage protein per well was $0.063 \mathrm{mg}$.
Table II. L-Arginine and L-ornithine Decarboxylation by Cytotoxic Macrophages

\begin{tabular}{cccl}
\hline $\begin{array}{c}\text { No. of } \\
\text { experiments }\end{array}$ & Substrate & Inhibitor* & ${ }^{14} \mathrm{CO}_{2}$ trapped $^{\ddagger}$ \\
\hline 6 & ${ }^{14} \mathrm{COOH}$ D,L-arginine & - & $0.49 \pm 0.10$ \\
3 & ${ }^{14} \mathrm{COOH}$ D,L-arginine & NMA & $0.96 \pm 0.11$ \\
1 & ${ }^{14} \mathrm{COOH}$ D,L-arginine & DFMA & 0.13 \\
1 & ${ }^{14} \mathrm{COOH}$ L-ornithine & - & 0.70 \\
& & & \\
\hline
\end{tabular}

* NMA, $50 \mu \mathrm{M}$; DFMA, 50 mM.

¥Values are mean rates \pm SEM (nanomoles per hour per milligram cell protein) determined over $24 \mathrm{~h}$ culture for three or four time points. $\$$ Mixture of D and L stereoisomers. Calculations made assuming D isomer is metabolically inert.

and II). With carboxyl-labeled L-ornithine as substrate, decarboxylation activity was roughly similar and within the same order of magnitude as for arginine. Because macrophages readily converted arginine to ornithine, but not vice versa, labeled carbon dioxide could arise directly from arginine or from L-ornithine when labeled arginine was the substrate. When NMA was added at a concentration which blocked fungistatic capability (8), arginine decarboxylation metabolism doubled (Table II). The same concentration of inhibitor markedly reduced nitrogen oxidation to nitrite and nitrate but did not affect arginase activity (Table I). It appeared that macrophage fungistatic capability was inversely correlated with decarboxylation metabolism.

Potential intermediates and products of polyamine synthesis were tested to determine whether they could replace arginine for macrophage fungistatic capability and nitrite production. These were: L-ornithine, agmatine, putrescine, spermine, spermidine, and canavanine. All were inactive in both assays (not shown).

The inhibitor of L-arginine decarboxylase, alpha-difluoromethylarginine (DFMA) (27) inhibited both labeled carbon dioxide production (Table II) and nitrite production (by 73\%) when L-arginine was the substrate. Inhibition of nitrite production occurred only at a high concentration $(50 \mathrm{mM})$, which produced some toxicity to $\mathrm{CM}$ after $24 \mathrm{~h}$ incubation. Thus, this inhibitor was not useful in dissociating the nitrogen oxidation pathway from decarboxylation metabolism. This result raises the possibility that activated murine macrophages possess arginine decarboxylase in addition to ornithine decarboxylase because DFMA does not inhibit the latter enzyme activity (28). Alternatively, radioactive carbon dioxide could arise by conversion of arginine to glutamate and then to alpha-ketoglutarate, which can be oxidized to $\mathrm{CO}_{2}$ in the tricarboxycyclic acid cycle.

\section{Discussion}

Within the past decade it was demonstrated unequivocally, primarily by Tannenbaum and colleagues, that mammals, including man, synthesized nitrate $(29,30)$. During careful balance studies on humans they recognized that nitrate synthesis was related to inflammation caused by incidental infections (30). Then it was shown that nitrate synthesis was dramatically enhanced by endotoxin (31). Stuehr and Marletta found that nitrite and nitrate production occurred in murine macro- 
phages (7). Furthermore, agents that were known to cause macrophage activation (e.g., mycobacterial infection + endotoxin) led to marked stimulation of nitrate synthesis in vivo (7). This effect was reproduced in vitro using gamma interferon, the $\mathrm{T}$ lymphocyte cytokine known to activate macrophages for cytotoxic capability $(6,32)$. Recent work by Hibbs et al. showed that nitrite and nitrate production by macrophages depended on extracellular L-arginine, which was converted to L-citrulline during this process (4). This work was important because it showed that nitrite production by macrophages was linked to their ability to cause selective metabolic defects in neoplastic target cells (4). These defects were characteristic for tumor cells, which were prevented from replicating by activated macrophages (33-37). Thus, the link between cell proliferation and nitrite synthesis was established. Work on L-arginine dependence for macrophage cytotoxicity for tumor cells was extended to include a microorganism, $C$. neoformans, demonstrating the broad spectrum of activity for this pathway (8).

In this report the metabolism of $\mathrm{L}$-arginine in activated macrophages was measured and correlated with functional capability to inhibit fungal proliferation. Murine macrophages consumed arginine at a high rate. L-arginine consumption, as an essential amino acid utilized for new protein synthesis, amounted to only a small fraction of the total arginine consumption (Table III). The bulk of arginine consumed was converted directly to L-ornithine and urea, which accumulated in the culture medium. This accounted for $\sim 96 \%$ of arginine metabolized by resident macrophages, and $70 \%$ of consumption by activated cells. Secretion of arginase by both resident and activated macrophages accounted for this metabolism. Arginase was not inhibited by NMA. The activity of arginase was similar whether or not macrophages were activated, therefore fungistatic. We found no evidence that arginase contributed to, or inhibited macrophage fungistatic capability apart from the obvious effect of depleting medium arginine. One could argue that arginine depletion leading to failure of macrophage fungistasis would be an artificial situation occurring in vitro in a closed system. Hibbs et al. proposed a function for macrophage arginase in regulating nitrogen oxidation reactions (4). This intriguing proposal remains an open question that merits further investigation.

In all cases there was a strong correlation between macrophage fungistasis and production of nitrite/nitrate. This pathway accounted for $\sim 30 \%$ of arginine utilization by CM, 10 times that of RM. In the absence of extracellular L-arginine, nitrite/nitrate production by $\mathrm{CM}$ was measurable, but was very low. This low rate of production may be due to metabo- lism of intracellular arginine and/or proteolysis yielding L-arginine. We could find no evidence that macromolecular arginine (poly-L-arginine, with 10,000-12,000 mol wt) supported nitrite/nitrate synthesis (not shown). Macrophage fungistasis did not occur under conditions of low level nitrogen oxidation, that is: $(a)$ in arginine-free medium, $(b)$ in the presence of NMA, $(c)$ or when resident macrophages were used. The rate of nitrite production was dependent on L-arginine concentration as was the degree of fungistasis (Figs. 2 and 3) (8). The direct correlation between the rate of production and the biological function of inhibiting replication is consistent with the hypothesis that macrophage fungistasis requires an ongoing elaboration of some endogenous antimicrobial which diffuses within the phagocyte and/or the proximate pericellular environment; further, that removal of inhibited fungi from this environment would be followed by resumption of proliferation. We observed both of these phenomena in our earlier studies on murine macrophage fungistasis (3).

Current results from Hibbs et al. (38), Marletta et al. (39), and Stuehr et al. (40), provide evidence that nitrogen oxidation yields the intermediate, nitric oxide. Nitric oxide may be responsible for biochemical lesions in neoplastic cells whose proliferation is inhibited by macrophages (38). There is evidence that this effector molecule may inhibit cell proliferation by reaction with iron which is coordinated with sulfide in prosthetic groups of particular membrane localized enzymes (41). This may explain the loss of iron from neoplastic cells in contact with activated macrophages $(35,37)$. It remains to be seen whether the same defects develop in microorganisms attacked by macrophages. Inhibition of critical iron-containing redox enzymes would provide an effective means for blocking replication in diverse pathogenic microbes.

Another important aspect of arginine metabolism with potential relevance to macrophage fungistatic capability is transport of amino acid into, and out of, the cell. We have found that arginine metabolism to nitrite/nitrate continues to occur at a high rate after arginine influx has been blocked (submitted for publication). This suggests that the enzymes(s) responsible for nitrogen oxidation may be located at the outer face of the plasma membrane where direct reaction occurs with arginine in extracellular fluid.

A recent study in our laboratory examined human alveolar macrophages for fungistatic capability and nitrogen oxidation metabolism (42). Using the same methods described here there was no evidence of citrulline, nitrite, or nitrate production by alveolar macrophages from 28 normal human volunteers. Yet macrophages from all subjects were fungistatic for cryptococci in a 48 hour coculture assay. Thus there may be significant

Table III. Pathways of L-arginine Metabolism in Macrophages

\begin{tabular}{|c|c|c|c|c|}
\hline \multirow[b]{2}{*}{ Pathway } & \multirow[b]{2}{*}{ Products } & \multicolumn{2}{|c|}{ Relative flux:* } & \multirow[b]{2}{*}{ Function } \\
\hline & & Resident $\mathbf{M} \phi$ & Cytotoxic $\mathbf{M} \phi$ & \\
\hline Arginase & L-Orn + urea & $96 \%$ & $69 \%$ & $?$ \\
\hline Nitrogen oxidation & $\mathrm{L}-\mathrm{Cit}+\mathrm{NO}_{2}^{-}+\mathrm{NO}_{3}^{-}$ & $0.7 \%$ & $29 \%$ & Inhibits cell proliferation \\
\hline Decarboxylase & Agmatine $+\mathrm{CO}_{2}$ & - $^{*}$ & $0.2 \%$ & Synthesis of polyamines \\
\hline Translation $^{\S}$ & Proteins & $<3 \%$ & $2 \%$ & Synthesis of new proteins \\
\hline
\end{tabular}

* Estimated from data in Tables I and II. ${ }^{\ddagger}$ Not done. ${ }^{\S}$ Assumed from L-arginine consumption not accounted for by the other pathways. 
species and/or body site differences in the biochemical mechanisms used by macrophages to inhibit replication of fungi. Studies in progress involve examining human peritoneal macrophages activated in vitro with lymphokines for their functional capability and possible nitrogen oxidation reactions.

The findings on murine macrophage oxidation of arginine guanidino nitrogen must ultimately be extended to in vivo studies. Activity of this pathway is likely reflected in total urinary nitrate excretion under conditions of constant dietary intake of nitrate (7). It is possible that a specific inhibitor such as NMA may selectively block nitrite/nitrate synthesis in vivo. Given this situation, the role of macrophage microbiostatic capability via this mechanism in the maintenance of a dormant infection could be investigated. Such an in vivo model in which a specific pertubation leads to reactivation disease would be very useful in studying the dynamics in the host-parasite relationship that contribute to maintaining microbes in a state of dormancy.

\section{Acknowledgments}

Our thanks to Donna Ross and Lewis Broadnax for technical assistance, and to Mary Ann Howard for manuscript preparation.

Supported by grants from the National Institutes of Health (AI-26188) and R. J. Reynolds-Nabisco Industries.

\section{References}

1. Brummer, E., P. A. Morozumi, D. E. Philpott, and D. A. Stevens. 1981. Virulence of fungi: correlation of virulence of Blastomyces dermatitidis in vivo with escape from macrophage inhibition of replication in vitro. Infect. Immun. 32:864-871.

2. Wu-Hsieh, B., and D. H. Howard. 1984. Inhibition of growth of Histoplasma capsulatum by lymphokine-stimulated macrophages. $J$. Immunol. 132:2593-2597.

3. Granger, D. L., J. R. Perfect, and D. T. Durack. 1986. Macrophage-mediated fungistasis in vitro: Requirements for intracellular and extracellular cytotoxicity. J. Immunol. 136:672-680.

4. Hibbs, J. B., Jr., R. R. Taintor, and Z. Vavrin. 1987. Macrophage cytotoxicity: Role for L-arginine deiminase and iminonitrogen oxidation to nitrogen. Science (Wash. DC). 235:473-476.

5. Hibbs, J. B., Jr., Z. Vavrin, and R. R. Taintor. 1987. L-arginine is required for expression of the activated expression of the activated macrophage effector mechanism causing selective metabolic inhibition intarget cells. J. Immunol. 138:550-565.

6. Ding, A. H., C. F. Nathan, and D. J. Stuehr. 1988. Release of reactive nitrogen intermediates and reactive oxygen intermediates from mouse peritoneal macrophages: Comparison of activating cytokines and evidence for independent production. J. Immunol. 141:2407-2412.

7. Stuehr, D. J., and M. A. Marletta. 1985. Mammalian nitrate biosynthesis: Mouse macrophages produce nitrite and nitrate in response of Escherichia coli lipopolysaccharide. Proc. Natl. Acad. Sci. USA. 82:7738-7742.

8. Granger, D. L., J. B. Hibbs, Jr., J. R. Perfect, and D. T. Durack. 1987. Specific amino acid (L-arginine) requirement for the microbiostatic activity of murine macrophages. J. Clin. Invest. 81:1129-1136.

9. Tissue Culture Standards Committee. 1970. Tissue Culture Media. In Vitro (Rockville). 6:93-94.

10. Granger, D. L., J. R. Perfect, and D. T. Durack. 1985. Virulence of Cryptococcus neoformans. Regulation of capsule synthesis by carbon dioxide. J. Clin. Invest. 76:508-516.

11. Granger, D. L., J. R. Perfect, and D. T. Durack. 1986. Macrophage-mediated fungistasis: Requirement for a macromolecular component in serum. J. Immunol. 137:693-701.

12. Mackaness, G. B., D. J. Auclair, and P. H. Lagrange. 1973.
Immunopotentiation with BCG. I. Immune response to different strains and preparations. J. Natl. Cancer Inst. 51:1655-1667.

13. Green, L. C., D. A. Wagner, J. Glogowski, P. L. Skipper, J. S. Wishnok, and S. R. Tannenbaum. 1982. Analysis of nitrate, nitrite, and $\left[{ }^{15} \mathrm{~N}\right]$ nitrate in biological fluids. Anal. Biochem. 126:131-138.

14. Peterson, G. L. 1977. A simplification of the protein assay method of Lowry et al which is more generally applicable. Anal. Biochem. 83:346-356.

15. Bartholomew, B. 1984. A rapid method for the assay of nitrate in urine using the nitrate reductase enzyme of Escherichia coli. Food Chem. Toxicol. 22:541-543.

16. Cole, J. A., and J. W. T. Wimpenny. 1968. Metabolic pathways for nitrate reduction in Escherichia coli. Biochem. Biophys. Acta. 162:39-48.

17. Baker, M. D., H. Y. Mohammed, and H. Veening. 1981. Reversed-phase ion-pairing liquid chromatographic separation and fluorometric detection of guanidino compounds. Anal. Chem. 53:16581662.

18. Schimke, R. T. 1970. Micromethods for the assay of argininosuccinate synthetase, arginosuccinase, and arginase. Methods Enzymol. 17:324-329.

19. Kung, J. T., S. B. Brooks, J. P. Jakway, L. L. Leonard, and D. W. Talmage. 1977. Suppression of in vitro cytotoxic response by macrophages due to induced arginase. J. Exp. Med. 146:665-672.

20. Currie, G. A. 1978. Activated macrophages kill tumor cells by releasing arginase. Nature (Lond.). 273:758-759.

21. Iyengar, R., D. J. Stuehr, and M. A. Marletta. 1987. Macrophage synthesis of nitrite, nitrate, and N-nitrosamines: Precursors and role of the respiratory burst. Proc. Natl. Acad. Sci. USA. 84:63696373.

22. Bremer, H. J., M. Duran, J. P. Kamerling, H. Pryzrembel, and S. K. Wadman. 1981. Disturbances of amino acid metabolism: clinical chemistry and diagnosis. Urban and Schwarzenberg, Baltimore. 203-220.

23. Lehrer, R. I., L. G. Ferrari, J. Patterson-Delafield, and T. Sorrell. 1980. Fungicidal activity of rabbit alveolar and peritoneal macrophages against Candida albicans. Infect. Immun. 28:1001-1008.

24. Ganz, T., M. E. Selsted, D. Szklark, S. S. L. Harwig, L. Daher, D. F. Bainton, and R. I. Lehrer. 1985. Defensins: Natural peptide antibiotics of human neutrophils. J. Clin. Invest. 76:1427-1435.

25. Sjoerdsma, A., and P. J. Schecter. 1984. Chemotherapeutic implications of polyamine biosynthesis inhibition. Clin. Pharmacol. Ther. 35:287-299.

26. Rzepczyk, C. M., A. J. Saul, and A. Ferrante. 1984. Polyamine oxidase-mediated intraerythrocytic killing of Plasmodium falciparum: evidence against the role of reactive oxygen metabolites. Infect. Immun. 43:238-244.

27. Bitonti, A. J., P. J. Casara, P. P. McCann, and P. Bey. 1987. Catalytic irreversible inhibition of bacterial and plant arginine decarboxylase activities by novel substrate and product analogues. Biochem. J. 242:69-74

28. Kierszenbaum, F., J. J. Wirth, P. P. McCann, and A. Sjoerdsma. 1987. Arginine decarboxylase inhibitors reduce the capacity of Trypanosoma cruzi to infect and multiply in mammalian host cells. Proc. Natl. Acad. Sci. USA. 84:4278-4282.

29. Green, L. C., K. Ruiz de Luzuriaga, D. A. Wagner, W. Rand, N. Istfan, V. R. Young, and S. R. Tannenbaum. 1981. Nitrate biosynthesis in man. Proc. Natl. Acad. Sci. USA. 78:7764-7768.

30. Green, L. C., S. R. Tannenbaum, and P. G. Goldman. 1981. Nitrate synthesis in the germ-free and conventional rat. Science (Wash. DC). 212:56-58.

31. Wagner, D. A., V. R. Young, and S. R. Tannenbaum. 1983. Mammalian nitrate biosynthesis: incorporation of ${ }^{15} \mathrm{NH}_{3}$ into nitrate is enhanced by endotoxin treatment. Proc. Natl. Acad. Sci. USA. $80: 4518-4521$.

32. Stuehr, D. J., and M. A. Marletta. 1987. Induction of nitrite/ nitrate synthesis in murine macrophages by BCG infection, lymphokines, or interferon gamma. J. Immunol. 139:518-525. 
33. Granger, D. L., R. R. Taintor, J. L. Cook, and J. B. Hibbs, Jr. 1980. Injury of neoplastic cells by murine macrophages leads to inhibition of mitochondrial respiration. J. Clin. Invest. 65:357-370.

34. Granger, D. L., and A. L. Lehninger. 1982. Sites of inhibition of mitochondrial electron transport in macrophage-injured neoplastic cells. J. Cell Biol. 95:527-535.

35. Hibbs, J. B., Jr., R. R. Taintor, and Z. Vavrin. 1984. Iron depletion: Possible cause of tumor cell cytotoxicity induced by activated macrophages. Biochem. Biophys. Res. Commun. 123:716-723.

36. Drapier, J. C., and J. B. Hibbs, Jr. 1986. Murine cytotoxic activated macrophages inhibit aconitase in tumor cells. Inhibition involves the iron-sulfur prosthetic group and is reversible. J. Clin. Invest. 78:790-797.

37. Wharton, M., D. L. Granger, and D. T. Durack. 1987. Mitochondrial iron loss from leukemia cells injured by macrophages: a possible mechanism for electron transport chain defects. J. Immunol. 141:1311-1317.

38. Hibbs, J. B., Jr., R. R. Taintor, Z. Vavrin, and E. M. Rachlin.
1988. Nitric oxide: A cytotoxic activated macrophage effector molecule. Biochem. Biophys. Res. Commun. 157:87-94.

39. Marletta, M. A., P. S. Yoon, R. Iyengar, C. D. Leaf, and J. S. Wishnok. 1988. Macrophage oxidation of L-arginine to nitrite and nitrate: nitric oxide is an intermediate. Biochemistry. 27:8706-8711.

40. Stuehr, D. J., S. S. Gross, I. Sukuma, R. Levi, and C. F. Nathan. 1989. Activated murine macrophages secrete a metabolite of arginine with the bioactivity of endothelium-derived relaxing factor and the chemical reactivity of nitric oxide. J. Exp. Med. 169:1011-1020.

41. Salerno, J. C., T. Ohnishi, T. Lim, and T. E. King. 1976. Tetranuclear and binuclear iron-sulfur clusters in succinate dehydrogenase: a method of iron quantitation by formation of paramagnetic complexes. Biochem. Biophys. Res. Commun. 73:833-840.

42. Cameron, M., D. Granger, W. Kozumbo, B. Weinberg, H. Koren, and D. Durack. 1989. Human alveolar macrophage mediated fungistasis occurs independently of $\mathrm{L}$-arginine oxidation. Clin. Res. 37:425A. (Abstr.) 